\title{
Enhanced Effects of Cortisol Administration on Episodic and Working Memory in Aging Veterans with PTSD
}

\author{
Rachel Yehuda ${ }^{*},{ }^{\prime, 2}$, Philip D Harvey', Monte Buchsbaum ${ }^{1,3}$, Lisa Tischler' and James Schmeidler,4 \\ 'The Traumatic Stress Studies Program, Psychiatry Department, The Mount Sinai School of Medicine, New York, NY, USA; ${ }^{2}$ The PTSD Program at \\ the James J Peters Bronx Veterans Affairs Medical Center, Bronx, NY, USA; ${ }^{3}$ The Neuroscience PET Laboratory, The Mount Sinai School of \\ Medicine, New York, NY, USA; ${ }^{4}$ The Center for Biomathematical Sciences, The Mount Sinai School of Medicine, New York, NY, USA
}

\begin{abstract}
Though both glucocorticoid alterations and memory impairments have been noted in posttraumatic stress disorder (PTSD), it is not clear if these phenomena are causally linked. As there is emerging evidence that these domains become further altered in PTSD with increasing age, it is of interest to examine these relationships in an older cohort. Aging (mean age, 62.7 \pm 8.9 ; range, 52-8I) combat veterans with $(n=13)$ and without $(n=17)$ PTSD received an intravenous bolus of $17.5 \mathrm{mg}$ hydrocortisone (cortisol), a naturally occurring glucocorticoid, or placebo in a randomized, double-blind manner, on two mornings approximately I-2 weeks apart. Neuropsychological testing to evaluate episodic and working memory performance was performed 75 min later. Cortisol enhanced episodic memory performance in both groups of subjects, but enhanced elements of working memory performance only in the PTSD + group. The preferential effect of cortisol administration on working memory in PTSD may be related to the superimposition of PTSD and age, as cortisol had impairing effects on this task in a previously studied, younger cohort. The findings suggest that there may be opportunities for developing therapeutic strategies using glucocorticoids in the treatment of aging combat veterans. Neuropsychopharmacology (2007) 32, 258I-259I; doi: I0.1038/sj.npp. I 30I380; published online 28 March 2007
\end{abstract}

Keywords: posttraumatic stress disorder; combat veterans; cortisol/glucocorticoids; memory performance; cognitive function; aging

\section{INTRODUCTION}

Glucocorticoids affect cognitive performance (Sauro et al, 2003; Het et al, 2005), and cognitive performance is often compromised in psychiatric disorders characterized by glucocorticoid alterations (Wolkowitz et al, 1990; Belanoff et al, 2001; Vythilingam et al, 2004). To the extent that memory problems are causally linked with glucocorticoid alterations, it might be possible to enhance cognitive performance using interventions that target glucocorticoid activity in brain.

In posttraumatic stress disorder (PTSD), both glucocorticoid alterations and impairments in memory performance have been demonstrated. A major glucocorticoid alteration in PTSD appears to be an increased responsiveness to glucocorticoids, evidenced by an enhanced sensitivity of Type II glucocorticoid receptors to in vivo and in vitro glucocorticoid challenge, that is often accompanied by reduced cortisol levels (Yehuda et al, 2004a, b; Rohleder et al, 2004; Yehuda, 2002). These neuroendocrine alterations in PTSD differ from those observed in major depression and normal aging, conditions that have been associated with

*Correspondence: Dr R Yehuda, Bronx VA OOMH, 130 West Kingsbridge Road, Bronx, NY 10468, USA, Tel: + I 7185849000 ext. 6964, Fax: + I 718 74I 4775, E-mail: Rachel.Yehuda@med.va.gov Received 31 May 2006; revised 13 December 2006; accepted 17 January 2007 reduced glucocorticoid responsiveness and increased cortisol levels (O'Brien et al, 1999; Sapolsky 2000; Lupien et al, 1999; Yehuda et al, 1996). The major cognitive decrements described in PTSD have involved performance on tests of episodic memory (Vasterling et al, 2002; Veltmeyer et al, 2005; Bremner et al, 1995; Yehuda et al, 1995). These deficits have implicated medial temporal circuits, particularly, the hippocampus, a region that has been shown to be responsive to glucocorticoids, involved in episodic memory, and manifesting structural and functional alterations in PTSD (Mirescu and Gould, 2006; Sauro et al, 2003; Het et al, 2005; Kitayama et al, 2005).

However, emerging evidence demonstrates that biologic alterations in PTSD are not necessarily static, and do appear to change with age. Memory impairments in PTSD appear to become more prominent with aging (Yehuda et al, 2005a). Compared to older veterans without PTSD, older combat veterans with PTSD show a greater decrement in aspects of memory that were demonstrated to be impaired in younger veterans with PTSD. Moreover, older veterans with PTSD also demonstrated a greater range of alterations in memory domains previously found to be unaffected, such as in immediate recall, acquisition of memory, cumulative learning, and active interference from previous learning compared to older veterans without PTSD. With respect to glucocorticoid alterations, cross-sectional and longitudinal studies demonstrated an even greater diminution in ambient cortisol levels over time in trauma survivors, a 
finding that is in the opposite direction of the progressive increases in cortisol described in aging (Yehuda et al, 2006c; Yehuda et al, in press). In contrast, older trauma survivors also showed a flattening of the circadian rhythm of cortisol, which is similar to what has been described in normal aging (Yehuda et al, in preparation; Yehuda et al, 2005b), suggesting a superimposition of aging with PTSD effects in older trauma survivors. In contrast, it does not appear that hippocampal volume in PTSD continues to decrease over time. Though the smaller hippocampal volume present in younger subjects with PTSD is similar to atrophy associated with normal aging processes, the failure of three published studies to detect group difference in elderly trauma survivors suggests that this biologic alteration may no longer be evident at a time when healthy subjects are not manifesting normal age-related atrophy in this region (Freeman et al, 2006; Yehuda et al, 2006a; Golier et al, 2005). These findings raise the question whether the increased cognitive decline in aging trauma survivors with PTSD is mediated by the same biologic mechanisms, eg hippocampal atrophy induced by age-related increases in glucocorticoid release (Sapolsky, 2000; Miller and O'Callaghan, 2005; Lupien et al, 2005; Golomb et al, 1996).

We recently reported that in younger subjects with PTSD, cortisol administration impaired performance on working memory (Grossman et al, 2006). These findings are consistent with the literature on the effects of cortisol administration in healthy volunteers, which has most often demonstrated impairing effects of cortisol on memory performance (see, for review, Sauro et al, 2003; Het et al, 2005). Yet, in predicting the effects of cortisol administration in older subjects, it is tempting to posit that opposite effects would be observed. Indeed, although an argument can be made that increased glucocorticoid sensitivity would result in an amplification of cortisol's negative effects, it might also be the case that as cortisol levels fail to increase in PTSD in aging persons, there is some protection from damaging effects of age-related hippocampal atrophy and memory decline.

In considering specific predictions with respect to glucocorticoid effects in any individual or cohort, there are many factors, including dose and timing of glucocorticoid administration, type of memory process being measured, and individual differences relating to clinical status and age that can affect this relationship (Roozendaal, 2002). With respect to dosing, higher doses of cortisol (eg $160 \mathrm{mg} /$ day using split doses to approximate circadian rhythm) were found to be generally more impairing than lower doses (eg $40 \mathrm{mg} /$ day), and doses that resulted in moderate levels of cortisol (eg $50 \mathrm{mg}$ /day) were more beneficial than those resulting in levels that are too low (eg $25 \mathrm{mg} /$ day) (Newcomer et al, 1999). In terms of timing, glucocorticoids are more beneficial when administered in the evening, when cortisol levels are naturally lower in the diurnal cycle than in the morning when they are naturally elevated (Lupien and Lepage, 2001; Lupien et al, 2002). Regarding memory processes, cortisol impairs performance when administered during memory retrieval but not if administered before learning (Het et al, 2005), and is more likely to affect adversely the recall of previously learned information but enhance learning of new information (Roozendaal et al, 2004). Cortisol also appears to impair memory for emotionally arousing material (Rimmele et al, 2003), but to be beneficial with respect to memory for neutral stimuli (Buchanan and Lovallo, 2001).

Despite the importance of these other factors, differences in clinical status and aging may be specifically relevant with respect to predictions of cortisol effects in aging subjects with PTSD. For example, the synthetic hormone, dexamethasone, has been shown to have a beneficial effect on memory performance in depression (Bremner et al, 2004a), but a deleterious effect on healthy volunteers, and no effect in younger subjects with PTSD (Bremner et al, 2004b). Dexamethasone acts primarily at the pituitary and results in a drastic reduction of endogenous cortisol, supporting the idea that memory effects are strongly influenced by ambient cortisol levels. To the extent that these findings are explained by respective differences in ambient cortisol levels associated with these clinical states, this would support the idea that cortisol effects on memory depend on ambient hormone levels. Changes in ambient cortisol levels associated with aging might also explain the differential effects of glucocorticoids associated with aging. For example, in contrast to effects typically observed in younger subjects, a study of normal elderly subjects showed no significant adverse effects of cortisol on a range of cognitive functions (Porter et al, 2002). Furthermore, in elderly subjects with a 5-year history of moderate cortisol levels, metyrapone treatment, which acutely decreases cortisol, significantly impaired memory performance, whereas in elderly subjects with a 5-year history of high cortisol levels, cortisol administration treatment significantly decreased delayed memory (Lupien et al, 2002). Stress-induced cortisol elevations also decreased delayed memory (Elzinga et al, 2005). Thus, there is evidence for an 'optimal level' of glucocorticoid functioning, deflections from which in either the lower or higher direction have predictable adverse effects on aspects of memory functioning.

This brief review highlights that glucocorticoid effects on memory function are multidetermined, but that one of the critical factors may certainly be ambient cortisol concentration, which in PTSD is often normal or even lower than normal, despite evidence for corticototropin-releasing hormone (CRH) hypersecretion (Yehuda, 2002). Accordingly, we hypothesized that glucocorticoid administration could be more beneficial in PTSD than in comparison subjects, particularly if administered at a low to moderate dose before learning new, neutral information.

To test this hypothesis, we utilized a randomized, doubleblind, crossover design in which we administered both an intravenous (i.v.) bolus of $17.5 \mathrm{mg}$ hydrocortisone succinate, a naturally occurring glucocorticoid, and placebo to aging combat veterans with and without PTSD. When administered as an i.v. bolus, this dose achieves plasma cortisol elevations that are high, but well within the physiologic range (Yehuda et al, 2006b). We examined several different aspects of memory performance, including both episodic and working memory, and related differences in performance to the biological activity of cortisol, indexed by suppression of adrenocorticotropin hormone (ACTH). 


\section{METHODS}

\section{Participants}

Thirty male veterans aged 52-81 years provided written informed consent to participate. The study was approved by the Institutional Review Boards of Mount Sinai School of Medicine, and of the Bronx Veterans Affairs.

Subjects were included in the PTSD group if they met the diagnostic criteria for current PTSD and were included in the PTSD - group if they were free from a current or past history of PTSD or major Axis I disorder. Subjects with PTSD were excluded if they had comorbid substance dependence, bipolar disorder, or psychosis, but not if they were suffering from current major depression or dysthymia or another anxiety disorder. Participants did not have any major medical, endocrinological, or neurological illness or head injury based on physical examination with laboratory tests, and were not taking antidepressants or other psychotropic medications.

\section{Clinical Assessments}

Information about traumatic life events was obtained using the Trauma History Questionnaire (Green, 1995). Subjects who endorsed a 'Criterion A' event, which, for the majority, included a combat or another military-related experience, were evaluated with the clinician administered PTSD scale (CAPS) (Blake et al, 1995). Other Axis I diagnoses were made using the structured clinical interview for DSM-IV (Spitzer et al, 1995). Diagnostic interviews were conducted by one of three licensed clinical psychologists with established interrater reliability. All diagnoses were reviewed at consensus conference by a team of psychologists and psychiatrists who were unaware of the biologic data.

\section{Neuroendocrine Testing and Biological Measures}

Cortisol challenge test. On two separate occasions, within 1-2 weeks apart, each participant received $17.5 \mathrm{mg}$ cortisol (hydrocortisone sodium succinate (Solucortef)) or placebo administered by a physician. To control for order effects, the occurrence of drug and placebo occurred randomly in each of the two groups on the first session and was then counterbalanced in each group separately by alternating between placebo and cortisol day.

Subjects were instructed to eat a light breakfast at 0600 and report to the laboratory by 0800 . A special sideperforated 20-gauge catheter with a stopcock for venous blood sampling was placed in the antecubital region, and a second catheter (24 gauge) placed in the contralateral antecubital region for delivery of cortisol or placebo. The catheter was kept patent with a slow saline drip. A baseline sample was collected $10 \mathrm{~min}$ before the injection of a bolus of saline or cortisol. Samples were obtained at several intervals postinjection for ACTH and cortisol determination (data presented elsewhere), and the generally lowest ACTH value (at $90 \mathrm{~min}$ postinjection) was used as a reflection of the neuroendocrine response to cortisol.

Neuroendocrine procedures and laboratory assays. Plasma ACTH levels were determined by radioimmunoassay using the ACTH IRMA kit from Nichols Institute Diagnostics (San Juan Capistrano, CA). The detection limit was
$0.02 \mathrm{ng} / \mathrm{ml}$. The intra- and inter-assay variability was 4.7 and $7.1 \%$, respectively.

To obtain a more informative measure of ambient cortisol than can be achieved with a baseline estimate on a test day, we asked subjects, several days before the testing procedure, to collect salivary samples at home at wake-up, at 30 and $60 \mathrm{~min}$ postawakening, and bedtime. Salivary cortisol levels were analyzed as described previously (Goenjian et al, 1996).

\section{Neuropsychological Testing}

We measured memory performance with a battery lasting approximately $30 \mathrm{~min}$, beginning at $75 \mathrm{~min}$ postinjection, after subjects had received a positron emission tomography scan (data presented elsewhere). The neuropsychiatric examination was designed to assess explicit and working memory tasks that have been previously demonstrated to be vulnerable to glucocorticoid administration (Kirschbaum et al, 1996; Newcomer et al, 1994; Wolkowitz et al, 1990). Episodic memory (verbal learning), as measured by immediate and delayed paragraph recall (ie Logical Memory from the Wechsler Memory Scale (third edition, WMS-III)) (Wechsler, 1997) was used. To minimize practice effects, two different paragraphs were administered in random order across conditions. Attention and maintenance working memory was assessed using the Digit Span Forward (DSF) subtest of the WMS-III. Manipulation working memory was measured by the Digit Span Backwards (DSB), and the letter number sequencing (LNS) subtests of the WMS-III. For the Digit Span and LNS subtests, only one version is available and was used on both test days.

\section{Data Analysis}

Group differences in baseline cortisol levels were evaluated using repeated measures analysis of variance (ANOVA) of wake-up, wake-up +30 , wake up +60 , and bedtime cortisol. Analysis of the response to cortisol proceeded in several steps. As each subject was tested twice, once on placebo and once on cortisol, the random assignment to a drug order was confounded with the interaction of drug by injection order. Preliminary repeated measures ANOVA were performed for each of the six dependent variables assessing effects of session (first, second), drug (placebo, cortisol) and their interaction, which was the injection order group (placebo first, cortisol first). For each dependent variable separately, the primary analysis was a comparison of the performance of two groups (PTSD +, PTSD-) on the two drugs. For each dependent variable separately, session and/or injection order were used as covariates when they were significant in the preliminary repeated measures analyses. This controlled for substantial session or injection order effects, without complicating the analyses by the inclusion of less relevant covariates. Other potential covariates, such as presence or absence of comorbid depression and anxiety were also examined and were not found to impact the data significantly. Effect sizes for the groups' drug vs placebo differences were calculated using Cohen's $d$, effect sizes for differences between groups were evaluated using $\eta^{2}$ (Cohen, 1988).

Correlational analyses were used to determine the relationships between the extent to which memory performance was altered in response to cortisol (expressed as the 
difference between performance following cortisol minus performance on the placebo day) and the ACTH levels at $90 \mathrm{~min}$ following cortisol (ie corresponding to the time where ACTH levels are maximally suppressed) expressed as the natural logarithm.

\section{RESULTS}

\section{Characteristics of the Sample}

Demographic and clinical characteristics of the sample, and results of statistical analyses of these variables, are reported in Table 1. Participants in the groups with and without PTSD were comparable in age and ethnic distribution. The groups differed with respect to the proportion of veterans who experienced combat trauma, but did not differ in age at focal trauma. The PTSD + group showed greater symptom severity in the intrusive, avoidance and hyperarousal subscales of the CAPS, and on total Mississippi PTSD Scale scores. Of the 13 participants with current PTSD, four had a comorbid diagnosis of major depressive disorder and seven had a diagnosis of another anxiety disorder. Table 1 also shows a trend-level main effect of Group $(p=0.055)$, reflecting generally lower cortisol levels in the PTSD + at

Table I Demographic and Trauma-Exposure Characteristics and Symptoms in Subjects with and without PTSD

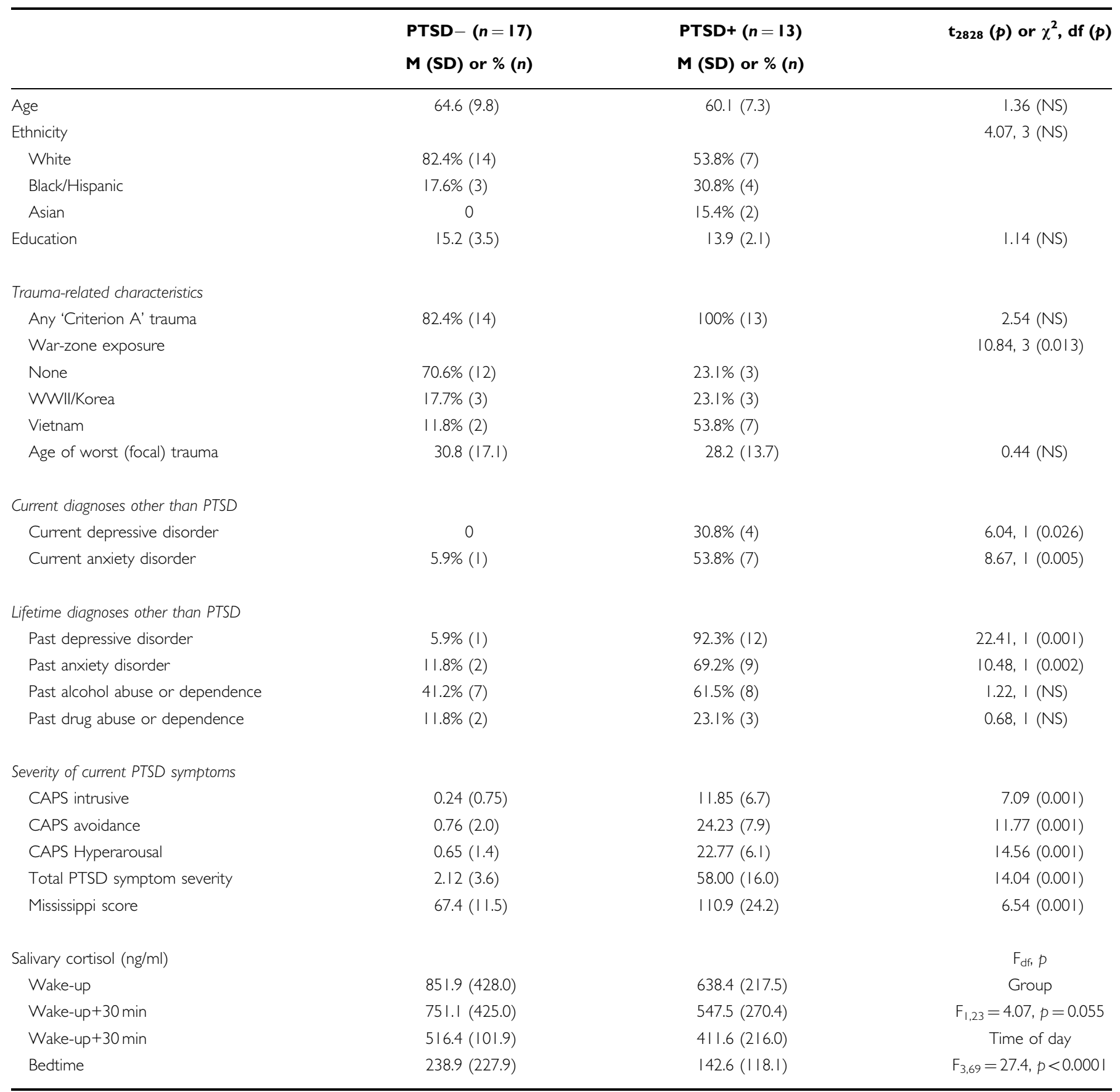

CAPS, clinician administered PTSD scale; NS, not significant; PTSD, posttraumatic stress disorder; SD, standard deviation. 
Table 2 Memory Performance by Day and Injection Order

\begin{tabular}{|c|c|c|c|c|c|c|}
\hline & \multicolumn{3}{|c|}{ Day } & \multicolumn{3}{|c|}{ Injection order } \\
\hline & $\begin{array}{c}\text { Session I mean } \\
\text { (SEM) }\end{array}$ & $\begin{array}{l}\text { Session } 2 \text { mean } \\
\text { (SEM) }\end{array}$ & $p$ & $\begin{array}{c}\text { Placebo/cortisol } \\
\text { mean (SEM) }\end{array}$ & $\begin{array}{c}\text { Cortisol/placebo } \\
\text { mean (SEM) }\end{array}$ & $p$ \\
\hline Percent savings & $92.27(1.9)$ & $90.93(2.1)$ & NS & $91.07(2.3)$ & $92.13(2.3)$ & NS \\
\hline Immediate recall & I3.47 (0.78) & $14.30(0.64)$ & NS & I3.20 (0.88) & | $4.57(0.88)$ & NS \\
\hline Delayed recall & II.53 (0.80) & $12.03(0.75)$ & NS & $|0.9|(0.95)$ & $12.60(0.95)$ & NS \\
\hline Digit Span Backward & $7.23(0.49)$ & $7.90(0.47)$ & 0.064 & $6.20(0.63)$ & $8.93(0.63)$ & 0.005 \\
\hline \multicolumn{7}{|l|}{ Digit Span } \\
\hline Total & I $6.57(0.90)$ & $18.13(0.81)$ & 0.006 & I5.23 (|.5) & $19.47(1.2)$ & 0.015 \\
\hline Letter number & $9.00(0.48)$ & $9.13(0.52)$ & NS & $7.70(0.67)$ & $10.43(0.67)$ & 0.007 \\
\hline
\end{tabular}

NS, not significant; SEM, standard error of the mean.

Columns for Session I and Session 2 present the mean values for the test data obtained on the first and second test day, respectively. The adjacent column to the right provides the level of significance for the comparison of the means from the first test day (Session I) and the second test day (Session 2) regardless of treatment. Columns for Injection Order present the mean values for the data obtained when cortisol was presented first, and when cortisol was presented second, respectively. The adjacent column to the right provides the level of significance for the comparison of the means based on Injection Order. The results for Session and Injection Order are presented as a preliminary analysis to identify variables that must be controlled for when performing the primary analysis concerning drug and group effects. In the absence of an effect of Injection Order, a main effect of Session would constitute a practice effect. Similarly, in the absence of a main effect of Session, a main effect of Injection Order indicates an effect of drug that is independent from a practice effect. The results of these analyses demonstrate that for the Digit Span Total variables, it was necessary to control for Session and Injection Order. For the LNS, no practice effects were observed per se, but the main effect of Injection Order indicated that it was necessary to control for this variable in the analyses comparing the two groups.

all time points, when the four salivary cortisol values were considered in a repeated measures ANOVA.

\section{Effects of Potential Effects of Injection Order}

Table 2 presents the results of the preliminary repeated measures analyses identifying the session and injection order variables to be controlled in the primary repeated measures analyses of group differences in the effects of cortisol on memory performance. The only measures in which there was a significant or trend-level order effect were the two subtests of the Digit Span test. For these two measures, and also for LNS, there was a significant effect of Injection Order, which suggested improved performance on the second assessment when cortisol was administered on the first test day. Accordingly, for analyses of these measures Injection Order was included as a covariate.

\section{Effect of Cortisol on Memory Performance}

There was a significant main effect of Group on retention (indexed by percent savings at delay on the Logical Memory Scale (LMS)), reflecting a significant decrement in the $\mathrm{PTSD}+$ compared to the PTSD- group $\left(\mathrm{F}_{1,28}=6.56\right.$, $p=0.016)$. This decrement was observed under both the placebo and cortisol conditions. Subjects without PTSD retained $95.8 \%$ of immediately acquired information following delay under placebo conditions, whereas those in the PTSD + group retained $89.2 \%$. The PTSD- group retained $85.2 \%$ on the cortisol day, compared to $94.1 \%$ in the PTSD + group. There was no main effect of Drug $\left(\mathrm{F}_{1,28}=1.42, \mathrm{NS}\right)$ and no Group $\times$ Drug interaction $\left(\mathrm{F}_{1,28}=0.21, \mathrm{NS}\right)$.

When the two components of this test, Immediate and Delayed recall, were analyzed as repeated measures, so that each subject had four observations (placebo and cortisol for each subtest), there was a significant main effect of Drug $\left(\mathrm{F}_{1,28}=8.9, p=0.006\right)$ with overall memory performance in both groups better on cortisol, as well as a main effect of Subtest $\left(\mathrm{F}_{1,28}=35.07, p<0.0001\right)$, indicating that participants in both groups scored lower in the delayed condition. As graphed in Figure 1, there was also a Group $\times$ Subtest interaction $\left(\mathrm{F}_{1,28}=6.56, p=0.016\right)$, demonstrating that performance in the delayed recall condition was worse for subjects in the PTSD + group. The absence of a Drug $\times$ Subtest interaction $\left(\mathrm{F}_{1,28}=1.42, \mathrm{NS}\right)$ indicated that, as expected, the effects of cortisol on each subtest were similar; indeed cortisol resulted in an increase of $18.6 \%$ in immediate recall and $18.4 \%$ in delayed recall when both groups were considered together.

Results for the DSF and DSB tests are graphed in Figure 2. For the DSF subtest, reflecting attention and maintenance working memory, repeated measures analysis of covariance (ANCOVA) demonstrated a main effect of Drug $\left(\mathrm{F}_{1,27}=11.68, p=0.002\right)$. Here too, after controlling for Injection Order, there was no Group $\times$ Drug interaction $\left(\mathrm{F}_{1,27}=2.33, p=0.14\right)$, and only a trend for a main effect of Group $\left(\mathrm{F}_{1,27}=3.07, p=0.09\right)$. There was a main effect of the covariate of Injection Order $\left(\mathrm{F}_{1,27}=6.10, p=0.02\right)$ and a Drug $\times$ Injection Order $\left(\mathrm{F}_{1,27}=9.86, p=0.004\right)$ interaction. As it is inappropriate to use ANCOVA when there is a strong interaction between the covariate and an independent variable, to better distinguish injection order effects across drug conditions, data from the cortisol and placebo days were analyzed separately with two-way univariate ANOVAs, using Group and Injection Order as main effects. On the placebo day for DSF, ANOVA revealed significant main effects of Group $\left(F_{1,29}=4.27, p=0.049\right)$ and Injection Order $\left(F_{1,29}=10.42, p=0.003\right)$, but no Group $\times$ Injection Order interaction $\left(\mathrm{F}_{1,29}=0.002\right.$, NS). In contrast, analysis of DSF scores on the cortisol day indicated no main effect of 


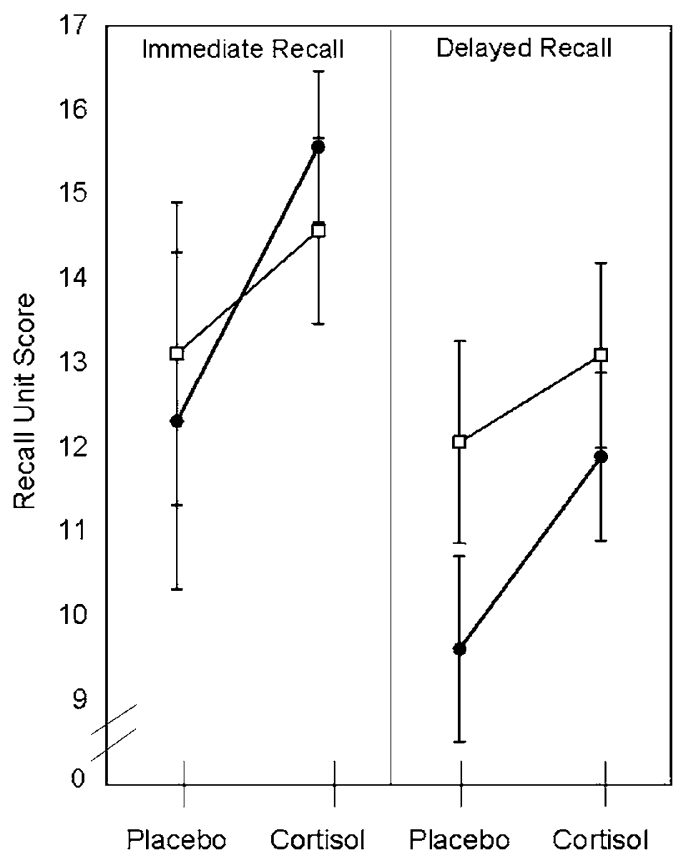

Figure I Effect of cortisol on immediate and delayed recall in participants with and without PTSD. Data represent the mean values (corrected for injection order) for number of correct responses on the Wechsler Logical Memory Scale. Data for the PTSD - and PTSD + groups are depicted by $\square$ and $\boldsymbol{\bullet}$, respectively. On Immediate Recall, the mean \pm standard error for PTSD $-(n=17)$ and PTSD $+(n=13)$ groups on the placebo day was $13.2+2.0$ and $12.3 \pm 1.8$, respectively, and $14.6 \pm 0.9$ and $15.6 \pm 1.1$ on the day of cortisol administration. On Delayed Recall, the mean \pm standard error for PTSD- and PTSD + groups on placebo day was $12.1 \pm 1.1$ and $9.6 \pm 1.2$, and $13.1 \pm 1.0$ and $11.9 \pm 1.1$ on the day of cortisol administration.

Group $\left(\mathrm{F}_{1,29}=1.31, \mathrm{NS}\right)$ or Injection Order $\left(\mathrm{F}_{1,29}=1.09\right.$, NS), and no Group $\times$ Injection Order interaction $\left(\mathrm{F}_{1,29}=1.21, \mathrm{NS}\right)$. These results reflect that on the placebo day, the PTSD + group performed significantly worse than the PTSD - group regardless of injection order (mean \pm SD: $8.69 \pm 3.51,10.82 \pm 2.30$ for PTSD + , PTSD -, respectively). However, the effect of injection order was to enhance performance in both groups on the placebo day when that assessment was preceded by cortisol administration (mean \pm SD: $10.33 \pm 3.14,12.22 \pm 1.79$ for PTSD + and PTSD-, respectively) compared to when it was administered first (mean \pm SD: $7.9 \pm 3.40,9.25 \pm 1.75$ for the PTSD + and PTSD-, respectively). The lack of a comparable enhanced performance when cortisol was administered on the second test day indicates that the improvement related to cortisol was not simply a practice effect, but rather that cortisol injection lead to a carryover effect of enhanced working memory performance (ie enhanced practice effect).

For DSB, reflecting manipulation as well as maintenance working memory demands, there was a nonsignificant trend for a main effect of Drug $\left(\mathrm{F}_{1,27}=3.87, p=0.06\right)$, no Drug $\times$ Group interaction $\left(\mathrm{F}_{1,27}=2.30, \mathrm{NS}\right)$ and no effect of Group $\left(F_{1,27}=1.11, N S\right)$. The covariate of Injection Order was significant $\left(\mathrm{F}_{1,27}=8.86, p=0.006\right)$, again reflecting better performance in both groups when cortisol was administered on the first day. There was no interaction between Injection Order and Drug.

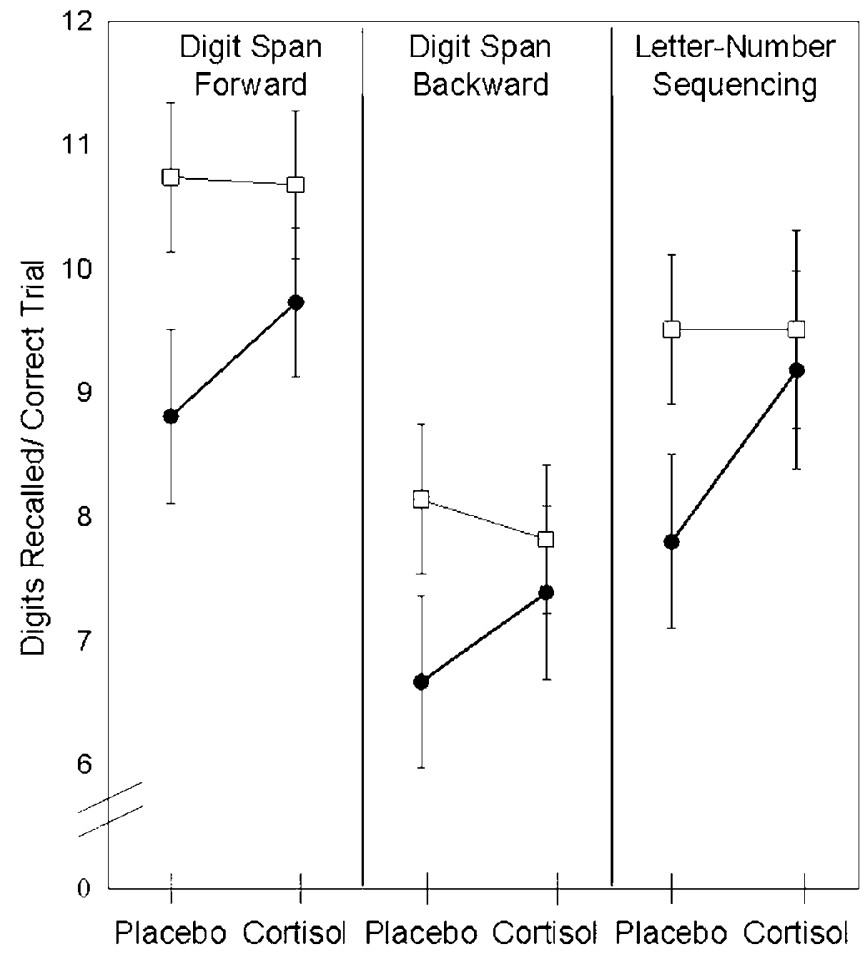

Figure 2 Effect of cortisol on DSF, Digit Span Backward, and LNS in participants with and without PTSD. Data represent the mean values (corrected for injection order) for digits recalled on the Wechsler Adult Intelligence Scale DSF and backward Subtests and the number of trials correctly completed on the Wechsler Adult Intelligence Scale LNS subtest. Data for the PTSD - and PTSD + groups are depicted by $\square$ and $\boldsymbol{0}$. respectively. On DSF, the mean \pm standard error of the mean for PTSD$(n=17)$ and PTSD $+(n=13)$ groups on the placebo day was $10.7 \pm 0.6$ and $8.8 \pm 0.7$, respectively, and $10.7 \pm 0.6$ and $9.7 \pm 0.6$ on the day of cortisol administration. On DSB, the mean \pm standard error for PTSD - and PTSD + groups on placebo day was $8.1 \pm 0.6$ and $6.7 \pm 0.7$, and $7.8 \pm 0.6$ and $7.4 \pm 0.7$ on the day of cortisol administration. On LNS, the mean \pm standard error for PTSD - and PTSD + groups on placebo day was $9.5 \pm 0.6$ and $7.8 \pm 0.7$, and $9.5 \pm 0.8$ and $9.2 \pm 0.8$ on the day of cortisol administration.

For LNS, a different pattern was observed, also graphed in Figure 2. Here, repeated measures ANCOVA demonstrated a significant Group $\times$ Drug interaction $\left(\mathrm{F}_{1,27}=4.98\right.$, $p=0.034)$ in the absence of a main effect of Drug $\left(\mathrm{F}_{1,27}=0.98, \mathrm{NS}\right)$ or Group $\left(\mathrm{F}_{1,27}=1.15, \mathrm{NS}\right)$. The interaction demonstrated that although subjects in the PTSD + group started out performing more poorly than those in the PTSD - group on this relatively difficult task, cortisol injection significantly improved their performance although having no effect in subjects in the PTSD- group. A main effect of Injection Order $\left(\mathrm{F}_{1,27}=7.99, p=0.009\right)$ was observed reflecting a higher performance in both groups if cortisol was administered before placebo. Here too, there was no interaction between Injection Order and Drug.

To examine whether the memory effects observed were moderated by ambient cortisol levels, we repeated the above analyses using the maximum cortisol level achieved following cortisol administration as a covariate. This reduced to a trend, but did not obliterate, the Group $\times$ Drug effect $\left(\mathrm{F}_{1,24}=3.90, p=0.06\right)$. However, there was a clearly significant effect of the covariate $\left(\mathrm{F}_{1,24}=5.18, p=0.032\right)$. When the analysis was repeated using the minimum ACTH 
response on the cortisol day as a covariate, this too had a small effect on the Group $\times$ Drug interaction $\left(\mathrm{F}_{1,24}=4.01\right.$, $p=0.056$ ), but ACTH levels were not found to be a significant covariate $\left(\mathrm{F}_{1,24}=0.65, \mathrm{NS}\right)$. In both analyses, there was no interaction between Group and the neuroendocrine covariate. These analyses suggest that ambient cortisol levels are generally related to working memory performance, comparably in both groups of subjects, but that the ACTH levels following cortisol, which likely represent an index of responsiveness to the cortisol challenge, may not be associated with performance on this type of task.

To provide a summary of the differences across tests and diagnostic groups in the effects of cortisol, the drug vs placebo effect sizes for the PTSD + and PTSD - samples graphed as Cohen's $d$, and effect sizes for PTSD $+v s$ PTSD - comparisons expressed as $\eta^{2}$, are presented in Figure 3. These findings show that the difference between drug and placebo on immediate and delayed recall was in the medium range for both subject groups. Similarly, the effects of cortisol on the working memory variables in the PTSD + samples were also in the medium range, whereas the effect sizes for the PTSD- group were negligible.

Relationships between changes in memory performance and an endocrine response to cortisol. In view of the apparent difference in the effects of cortisol on different aspects of memory performance across the two subject samples, we attempted to establish the biological validity of the cortisol challenge procedure. We present two scatterplots that depict the most divergent contrast in the effects of cortisol on episodic and working memories. There was a significant correlation between change in immediate recall and ACTH following cortisol administration $(r=-0.458$, $\mathrm{df}=25, p=0.016$; Figure 4, panel a). It is clear that both groups had a similar response to cortisol administration from the similar slopes in the two groups (for PTSD + $r=-0.48$; PTSD $-r=-0.43$ ). For descriptive purposes, a similar scatterplot for change scores on LNS, the only test with a significant Group $\times$ Drug interaction, is presented in Figure 4, panel $\mathrm{b}$. The scatterplot clearly suggests that there is no relationship between the ACTH response and change in LNS in the PTSD - or PTSD + groups (for PTSD + $r=-0.17$; PTSD $-r=-0.014$ ).

\section{DISCUSSION}

The main finding of this study is that an i.v. bolus of $17.5 \mathrm{mg}$ cortisol enhanced episodic memory performance in both groups, but on a test that involves both maintenance and manipulation of working memory, cortisol only had beneficial effects in the PTSD + group. That the effect of cortisol in this older sample was generally to improve memory performance is evidenced by the significant main effects of drug observed on the immediate and delayed recall on the LMS and the trend-level effect of cortisol for attention as measured by DSF. But with respect to the LNS, the Group $\times$ Drug interaction occurred in the absence of a main effect of Drug or Group, suggesting that although subjects in the PTSD + group started out performing more poorly than controls on this relatively difficult task, cortisol

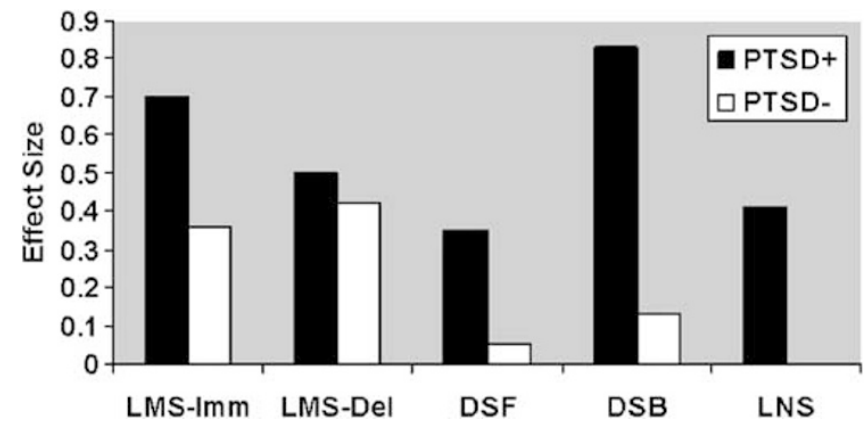

Figure 3 Effect sizes for cortisol effects on cognitive tests in the PTSD + and PTSD - groups. Data represent the effect sizes for the PTSD + group (dark bars) and PTSD - groups (white bars). Effect size (d) was calculated as the absolute value of the difference between the means divided by the $\mathrm{SD}$ of the difference, which in this case was on the mean difference in performance (cortisol minus placebo day) divided by the SD of the difference. The corresponding values of partial $\eta^{2}$, a measure of effect sizes for interaction effects, are LMS-Imm $=0.058$; LMS-Del $=0.023$; $\mathrm{DSF}=0.079 ; \mathrm{DSB}=0.079$; and $\mathrm{LNS}=0.156$, respectively. $\mathrm{LMS}-\mathrm{Imm}$ : Wechsler Logical Memory Scale, Immediate Recall Subscale; LMS-Del, Wechsler Logical Memory Scale, Delayed Recall Subscale; DSF: Wechsler Adult Intelligence Scale DSF; DSB: Wechsler Adult Intelligence Scale DSB Subtest, LNS: Wechsler Adult Intelligence Scale LNS Subtest.
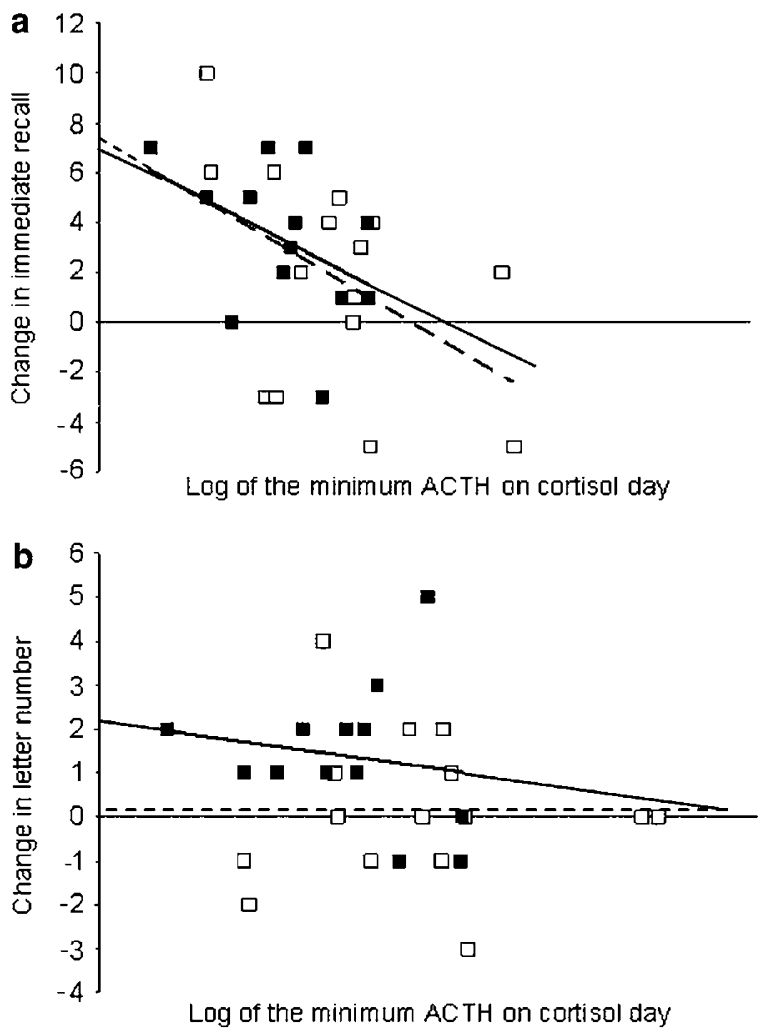

Figure 4 Relationship between extent ACTH suppression following cortisol administration and cortisol-placebo differences in memory performance. In both panel (a) and panel (b), the PTSD + group $(n=13)$ is represented by $\mathbf{\square}$, and the control group $(n=15)$ by $\square$. For panel (a) the solid line shows the trend line for the PTSD + group, $r=-0.189$, and the dotted line shows the trend line for the control group $r=-0.228$. For panel (b), the solid line shows the trend line for the PTSD + group, $r=-0.028$, and the dotted line shows the trend line for the control group $r=0.00002$. Change in performance was calculated by subtracting performance on the cortisol day minus performance on the placebo day. 
injection significantly improved their performance although having no effect in the controls. Significant effects of cortisol were not seen in relation to the Digit Span Total test, after controlling for injection order. It is somewhat surprising that subjects with PTSD showed a preferential response on the LNS than the Digit Span Total as both tasks purported to measure working memory. In evaluating this discrepancy, it should be kept in mind that these results may have a component of 'task specificity', as observed both by the absence of a practice effect on the LNS, and a relatively more impaired performance at baseline on the Digit Span Total in the PTSD + group. These factors, together, may have resulted in a slightly different response to cortisol administration and this issue does require further investigation. Also of importance is the fact that DSB performance was the task that was most strongly affected by cortisol in the PTSD + group (Figure 3), with the lack of difference between PTSD + and PTSD - groups likely being nonsignificant because of low power alone.

As the PTSD + group performed more poorly than the PTSD - group on nearly every measure at baseline, the improvement with cortisol may partially reflect poor performance at the outset. With respect to episodic memory, both groups of veterans scored well below the maximum possible score, which may account for why both groups improved on this measure. However, the differential effects of cortisol in PTSD on a measure of working memory cannot be attributed exclusively to lower baseline memory performance in PTSD. This is because there was also a beneficial effect of receiving cortisol before placebo as evidenced by their higher Digit Span and LNS scores on the placebo day if they had first received cortisol. As the order of administration for cortisol vs placebo was randomized across subjects, these findings are best interpreted as representing a benefit of cortisol, rather than a practice effect. Although it could be argued that the cortisol effect in the PTSD group is confounded with the repetition of these tests, there did not appear to be a practice effect in either the PTSD + or PTSD - group. Arguably, subjects in the PTSD - group could have also shown some cortisol-induced imprinting, but that they did not further support the specificity of the response to cortisol in the PTSD group in this test.

The Group $\times$ Drug interaction observed in this older cohort represents an effect of glucocorticoids that is opposite to what we observed previously in a cohort approximately 30 years younger, in which there was also a significant Group $\times$ Drug interaction reflecting a decline in performance following cortisol in PTSD and no effect in controls (Grossman et al, 2006). In that study, PTSD + subjects did not start out performing more poorly than participants without PTSD on working memory. That older subjects with PTSD show a greater deficit at baseline on working memory may reflect effects accruing from the constellation of biologic alterations in PTSD over time, or an accelerated age-related process. Accordingly, the beneficial effects of low-dose glucocorticoids may not be moderated by PTSD directly, but only become more pronounced in PTSD to the extent that the pattern of cortisol-related benefits of memory vary based on endocrine status or other individual differences of the subject.
A major limitation of the current study is the small sample sizes. However, estimated effect sizes for the statistically significant results were in the moderate to large range. Accordingly, it is unlikely that the lack of beneficial effects of cortisol on working memory in subjects without PTSD can be attributed to low power. In fact, the effects for subjects without PTSD were close to zero and would have only been detectible with an implausibly large sample size. Rather, the findings suggest that cortisol has differential effects on different aspects of memory as a function of clinical or neuroendocrine status of subjects. Indeed, the observation that ambient cortisol levels following cortisol administration were found to be a significant covariate in the analysis of the LNS data supports the conclusion that the beneficial effects of cortisol on memory performance in PTSD may be at least partially linked to correcting the lower levels of basal glucocorticoids. On the other hand, as neither the addition of ambient cortisol or the ACTH response to challenge obliterated the Group $\times$ Drug interaction, but only reduced it somewhat, it may be that the differential effects of cortisol administration on memory are mediated by the actions of other neuropeptides, such as CRH or arginine-vasopressin (AVP), which are directly affected by glucocorticoid regulation, or other neurotransmitters such as norepinephrine or dopamine which have been shown to be altered in PTSD (O'Donnell et al, 2004; Glover et al, 2003; Segman et al, 2002; Yehuda et al, 1998). Effects of cortisol on dopamine may be particularly relevant, as dopamine receptors have been demonstrated to be involved in working memory (Sawaguchi and Goldman-Rakic, 1991). Furthermore, both animal and human studies have recently confirmed direct relationships between manipulations that increase or decrease glucocorticoid release and brain dopamine release (Pruessner et al, 2004; Pacak et al, 2002; Rouge-Pont et al, 1998).

Interestingly, the results of the above-mentioned ANCOVA demonstrated that the relationship between cortisol and memory performance did not differ in the PTSD + and PTSD - groups. Thus, although the groups differed in the effect of cortisol on memory, this most likely reflects a group difference in ambient glucocorticoid levels or glucocorticoid receptor responsiveness. Indeed, in many respects, cortisol administration had comparable effects in the two groups. For example, cortisol administration not only improved episodic memory in both the PTSD + and PTSD - groups, but these improvements were similarly associated with responsiveness to cortisol as reflected by the $\log$ of the minimum ACTH level (ie reflecting maximum negative feedback effects of cortisol).

We have previously reported that subjects in this study showed an exaggerated suppression of ACTH in response to this dose of cortisol (Yehuda et al, 2006b). However, for the PTSD + group, the physiological dose of cortisol administration improved memory performance to the point where they were no longer performing significantly less well than subjects in the PTSD - group. However, with respect to performance on the Digit Span Total and LNS, the improved performance after cortisol administration did not leave PTSD patients performing, as well as the healthy controls at baseline, even though it offered virtually no advantage to subjects in the PTSD - group. One explanation for this apparent discrepancy is that alterations in episodic memory 
may be state-related (Yehuda et al, 2006c), and therefore constitute less stable consequences of enduring biological alterations.

The differential effects of cortisol in the PTSD + and PTSD - groups in working memory may implicate brain structures and circuitry outside the medial-temporal regions, such as in the anterior frontal lobe, as relevant to PTSD pathophysiology, and might also suggest an increasing role for these structures in PTSD with age. As recent studies demonstrate a particular role for both the dorsolateral prefrontal cortex and superior parietal cortex in tasks requiring the manipulation of working memory (Crone et al, 2006; Narayanana et al, 2005; Rypma and D'Esposito, 2003; Wager and Smith, 2003) particularly in aging subjects (Jennings et al, 2006; Kwee and Nakada, 2003; MacPherson et al, 2002; Rypma et al, 2001; Hazlett et al, 1998), these regions should be examined in aging subjects with PTSD. Glucocorticoid-induced impairments in memory performance, particularly declarative and episodic memory, have also been associated with reduced blood flow in the medial temporal lobe (de Quervain et al, 2003). However, insofar as PTSD + subjects showed enhanced suppression to ACTH on this challenge (Yehuda et al, 2006b), it may be that the preferential effect to cortisol administration on working memory reflects increased glucocorticiod sensitivity in the anterior frontal lobe region, a region recently found to be sensitive to the effects of a single dose of cortisol in healthy volunteers in at least two separate reports (Hsu et al, 2003; Monk and Nelson, 2002). Indeed, although glucocorticoid receptors are well known for their presence in the hippocampus, they are also present in the frontal cortex (Meaney and Aitken, 1985; Diorio et al, 1993; Watzka et al, 2000), and may be preferentially sensitive in PTSD.

Finally, the findings may have treatment implications. Although the beneficial effects of glucocorticoids on memory performance has not been uniformly observed across studies of nonpsychiatric subjects, and even in younger subjects with PTSD, their ameliorative effects in the current study are consistent with current pharmacologic strategies aimed at targeting PTSD symptoms. Specifically, glucocorticoid administration has been shown to prevent the development of traumatic memories when administered prophylactically in the immediate aftermath of trauma exposure (Schelling et al, 2001, 2004a, b), and also to decrease the intensity of intrusive memories when administered to persons with chronic PTSD (Aerni et al, 2004). Importantly, these effects have been attributed to the impairing effects of cortisol on emotional memory retrieval, and not the enhancing effects of glucocorticoids on memory per se. This distinction is noteworthy as the glucocorticoid effects on emotional memories, compared to neutral ones, may not be affected by aging (Golier et al, 2002, 2003). Regardless, insofar as glucocorticoid levels in the immediate aftermath and chronic PTSD have been reported as lower, the findings in aggregate offer proof of principle for the rationality of pursuing glucocorticoid-related treatment strategies in PTSD. Accordingly, it would be critical to examine neural correlates of cortisol administration in PTSD at baseline, in response to cognitive challenges, and to treatment. The current findings underscore the fact that it is not advisable to extrapolate from normal studies of aging that cortisol toxicity results in PTSD-related cognitive deficits. Doing so may result in a missed opportunity to exploit the potentially beneficial effects of cortisol on cognition and possibly symptom reduction in PTSD.

\section{ACKNOWLEDGEMENTS}

This work was supported by a VA Merit Review Grant (RY) and, in part by a grant (5 M01 RR00071) for the Mount Sinai General Clinical Research Center from the National Institute of Health. We thank Drs Julia Golier, Robert Grossman, and Linda Bierer for facilitating various aspects of this proposal, such as subject recruitment, medical clearance, and oversight of psychiatric diagnoses, and Drs Iouri Makotkine, Ren Kui Yang, and Song Ling Guo for laboratory determinations. We also thank Karina Stavitsky, Sarah Brand, and Adam Morris for help in subject coordination, data entry, and manuscript preparation.

\section{REFERENCES}

Aerni A, Traber R, Hock C, Roozendaal B, Schelling G, Papassotiropoulos A et al (2004). Low-dose cortisol for symptoms of posttraumatic stress disorder. Am J Psychiatry 161: $1488-1490$.

Belanoff JK, Kalehzan M, Sund B, Fleming Ficek SK, Schatzberg AF (2001). Cortisol activity and cognitive changes in psychotic major depression. Am J Psychiatry 158: 1612-1616.

Blake DD, Weathers FW, Nagy LM, Kaloupek DG, Klauminzer G, Charney DS et al (1995). A clinician rating scale for assessing current and lifetime PTSD: the CAPS-1. Behav Ther 13: 187-188.

Bremner JD, Randall P, Scott TM, Bronen RA, Seibyl JP, Southwick SM et al (1995). MRI-based measurement of hippocampal volume in patients with combat-related posttraumatic stress disorder. Am J Psychiatry 152: 973-981.

Bremner JD, Vythilingam M, Vermetten E, Anderson G, Newcomer JW, Charney DS (2004a). Effects of glucocorticoids on declarative memory function in major depression. Biol Psychiatry 55: 811-815.

Bremner JD, Vythilingam M, Vermetten E, Afzal N, Nazeer A, Newcomer JW et al (2004b). Effects of dexamethasone on declarative memory function in posttraumatic stress disorder. Psychiatry Res 129: 1-10.

Buchanan TW, Lovallo WR (2001). Enhanced memory for emotional material following stress-level cortisol treatment in humans. Psychoneuroendocrinology 26: 307-317.

Cohen J (1988). Statistical Power Analyses for the Behavioral Sciences, 2nd edn. Lawrence Erlbaum Ass: Hillside, NJ.

Crone EA, Wendelken C, Donohue S, van Lijenhorst L, Bunge SA (2006). Neurocognitive development of the ability to manipulate information in working memory. PNAS 103: 9315-9320.

de Quervain DJ, Henke K, Aerni A, Treyer V, McGaugh JL, Berthold $\mathrm{T}$ et al (2003). Glucocorticoid-induced impairment of declarative memory retrieval is associated with reduced blood flow in the medial temporal lobe. Eur J Neurosci 17: 1296-1302.

Diorio D, Viau V, Meaney MJ (1993). The role of the medial prefrontal cortex (cingulate gyrus) in the regulation of hypothalamic-pituitary-adrenal responses to stress. J Neurosci 13: 3839-3847.

Elzinga BM, Bakker A, Bremner JD (2005). Stress-induced cortisol elevations are associated with impaired delayed, but not immediate recall. Psychiatry Res 134: 211-223.

Freeman T, Kimbrell T, Booe L, Myers M, Cardwell D, Lindquist $\mathrm{DM}$ et al (2006). Evidence of resilience: neuroimaging in former POWs. Psychiatry Res 146: 59-64. 
Goenjian AK, Yehuda R, Pynoos RS, Steinber AM, Tashjian M, Yang RK et al (1996). Basal cortisol, dexamethasone suppression of cortisol, and MHPG in adolescents after the 1988 earthquake in Armenia. Am J Psychiatry 153: 929-934.

Glover DA, Powers MB, Bergman L, Smits JA, Teich MJ, Stuber M (2003). Urinary dopamine and turn bias in traumatized women with and without PTSD symptoms. Behav Brain Res 144: 137-141.

Golomb J, Kluger A, de Leon MJ, Ferris SH, Mittelman M, Cohen J et al (1996). Hippocampal formation size predicts declining memory performance in normal aging. Neurology 47: 810-813.

Golier JA, Yehuda R, Lupien SJ, Harvey PD, Grossman R, Elkin A (2002). Memory performance in Holocaust survivors with posttraumatic stress disorder. Am J Psychiatry 159: 1682-1688.

Golier JA, Yehuda R, Lupien SJ, Harvey PD (2003). Memory for trauma-related information in Holocaust survivors with PTSD. Psychiatry Res 121: 133-143.

Golier JA, Yehuda R, De Santi S, Segal S, Dolan S, de Leon MJ (2005). Absence of hippocampal volume differences in survivors of the Nazi Holocaust with and without PTSD. Psychiatry Res 139: 53-64.

Green BL (1995). Psychometric review of Trauma History Questionnaire (Self-Report). In: BH Stamm (ed). Measurement of Stress, Trauma, and Adaptation. Sidran Press: Lutherville, MD.

Grossman R, Yehuda R, Golier J, McEwen B, Harvey P, Maria NS (2006). Cognitive effects of intravenous hydrocortisone in subjects with PTSD and healthy control subjects. Ann NY Acad Sci 1071: 410-421.

Hazlett EA, Buchsbaum MS, Mohs RC, Spiegel-Cohen J, Wei TC, Azueta $\mathrm{R}$ et al (1998). Age-related shift in brain region activity during successful memory performance. Neurobiol Aging 19: 437-445.

Het S, Ramlow G, Wolf OT (2005). A meta-analytic review of the effects of acute cortisol administration on human memory. Psychoneuroendocrinology 30: 771-784.

Hsu FC, Garside MJ, Massey AE, McAllister-Williams RH (2003). Effects of a single dose of cortisol on the neural correlates of episodic memory and error processing in healthy volunteers. Psychopharmacology 167: 431-442.

Jennings JR, van der Veen FM, Meltzer CC (2006). Verbal and spatial working memory in older individuals: a positron emission tomography study. Brain Res 1092: 177-189.

Kirschbaum C, Wolf OT, May M, Wippich W, Hellhammer DH (1996). Stress- and treatment-induced elevations of cortisol levels associated with impaired declarative memory in healthy adults. Life Sci 58: 1475-1483.

Kitayama N, Vaccarino V, Kutner M, Weiss P, Bremner JD (2005). Magnetic resonance imaging (MRI) measurement of hippocampal volume in posttraumatic stress disorder: a meta-analysis. J Affect Disord 88: 79-86.

Kwee IL, Nakada T (2003). Dorsolateral prefrontal lobe activation declines significantly with age - functional NIRS study. J Neurol 250: 525-529.

Lupien SJ, Lepage M (2001). Stress, memory, and the hippocampus: can't live with it, can't live without it. Behav Brain Res 127: 137-158.

Lupien SJ, McEwen BS, Meaney M (1999). Increased cortisol levels and impaired cognition in human aging. Rev Neurosci 10: 117-139.

Lupien SJ, Wilkinson CW, Briere S, Ng Ying Kin NM, Meaney MJ, Nair NP (2002). Acute modulation of aged human memory by pharmacological manipulation of glucocorticoids. J Clin Endocrinol Metab 87: 3798-3807.

Lupien SJ, Schwartz G, Ng YK, Fiocco A, Wan N, Pruessner JC et al (2005). Douglas hospital longitudinal study of normal and pathological aging. J Psychiatry Neurosci 30: 328-334.
MacPherson SE, Phillips LH, Della Sala S (2002). Age, executive function, and social decision making: a dorsolateral prefrontal theory of cognitive aging. Psychol Aging 17: 598-609.

Meaney MJ, Aitken DH (1985). $\left[{ }^{3} \mathrm{H}\right]$ Dexamethasone binding in rat frontal cortex. Brain Res 328: 176-180.

Miller DB, O'Callaghan JP (2005). Aging, stress and the hippocampus. Ageing Res Rev 4: 123-140.

Mirescu C, Gould E (2006). Stress and adult neurogenesis. Hippocampus 16: 233-238.

Monk CS, Nelson CA (2002). The effects of hydrocortisone on cognitive and neural function: a behavioral and event-related potential investigation. Neuropsychopharmacology 26: 505-519.

Narayanana NS, Prabhakaran V, Bunge SA, Christoff K, Fine EM, Gabrieli JD (2005). The role of the prefrontal cortex in the maintenance of verbal working memory: an event-related FMRI analysis. Neuropsychology 19: 223-232.

Newcomer JW, Craft S, Hershey T, Askins K, Bardgett ME (1994). Glucocorticoid-induced impairment in declarative memory performance in adult humans. J Neurosci 14: 2047-2053.

Newcomer JW, Selke G, Melson AK, Hershey T, Craft S, Richards K et al (1999). Decreased memory performance in healthy humans induced by stress-level cortisol treatment. Arch Gen Psychiatry 56: $527-533$.

O’Brien JT, Lloyd A, McKeith I, Gholkar A, Ferrier N (1999). A longitudinal study of hippocampal volume, cortisol levels, and cognition in older depressed subjects. Am J Psychiatry 161: 2081-2090.

O’Donnell T, Hegadoren KM, Coupland NC (2004). Noradrenergic mechanisms in the pathophysiology of post-traumatic stress disorder. Neuropsychobiology 50: 273-283.

Pacak K, Tjurmina O, Palkovits M, Goldstein DS, Koch CA, Hoff T et al (2002). Chronic hypercortisolemia inhibits dopamine synthesis and turnover in the nucleus accumbens: an in vivo microdialysis study. Neuroendocrinology 76: 148-157.

Porter RJ, Barnett NA, Idey A, McGuckin EA, O’Brien JT (2002). Effects of hydrocortisone administration on cognitive function in the elderly. J Psychopharmacol 16: 65-71.

Pruessner JC, Champagne F, Meaney MJ, Dagher A (2004). Dopamine release in response to a psychological stress in humans and its relationship to early life maternal care: A Positron Emission Tomography Study Using [11C]Raclopride. J Neuroscience 24: 2825-2831.

Rimmele U, Domes G, Mathiak K, Hautzinger M (2003). Cortisol has different effects on human memory for emotional and neutral stimuli. Neuroreport 14: 2485-2488.

Rohleder N, Joksimovic L, Wolf JM, Kirschbaum C (2004). Hypocortisolism and increased glucocorticoid sensitivity of pro-inflammatory cytokine production in Bosnian war refugees with posttraumatic stress disorder. Biol Psychiatry 55: 745-751.

Roozendaal B, Hahn EL, Nathan SV, de Quervain DJ, McGaugh JL (2004). Glucocorticoid effects on memory retrieval require concurrent noradrenergicactivity in the hippocampus and basolateral amygdala. J Neurosci 24: 8161-8169.

Roozendaal B (2002). Stress and memory: opposing effects of glucocorticoids on memory consolidation and memory retrieval. Neurobiol Learn Mem 78: 578-595.

Rouge-Pont F, Deroche V, Le Moal M, Piazza PV (1998). Individual differences in stress-induced dopamine release in the nucleus acumens are influenced by corticosterone. Eur J Neurosc 10: 3903-3907.

Rypma B, D’Esposito M (2003). A subsequent-memory effect in dorsolateral prefrontal cortex. Brain Res Cogn Brain Res 16: 162-166.

Rypma B, Prabhakaran V, Desmond JE, Gabrieli JD (2001). Age differences in prefrontal cortical activity in working memory. Psychol Aging 16: 371-384.

Sapolsky RM (2000). Glucocorticoids and hippocampal atrophy in neuropsychiatric disorders. Arch Gen Psychiatry 57: 925-935. 
Sauro MD, Jorgensen RS, Pedlow CT (2003). Stress, glucocorticoids, and memory: a meta-analytic review. Stress 6: 235-245.

Sawaguchi T, Goldman-Rakic PS (1991). D1 dopamine receptors in prefrontal cortex: involvement in working memory. Science 251: 947-950.

Schelling G, Briegel J, Roozendaal B, Stoll C, Rothenhausler HB, Kapfhammer HP (2001). The effect of stress doses of hydrocortisone during septic shock on posttraumatic stress disorder in survivors. Biol Psychiatry 50: 978-985.

Schelling G, Kilger E, Roozendaal B, de Quervain DJ, Briegel J, Dagge A et al (2004a). Stress doses of hydrocortisone, traumatic memories, and symptoms of posttraumatic stress disorder in patients after cardiac surgery: a randomized study. Biol Psychiatry 55: 627-633.

Schelling G, Roozendaal B, De Quervain DJ (2004b). Can posttraumatic stress disorder be prevented with glucocorticoids? Ann NY Acad Sci 1032: 158-166.

Segman RH, Cooper-Kazaz R, Macciardi F, Goltser T, Haifon Y, Dobroborski T et al (2002). Associaton between the dopamine transporter gene and posttraumatic stress disorder. $\mathrm{Mol}$ Psychiatry 7: 903-907.

Spitzer RL, Gibbon M, Williams JBW (1995). Structured Clinical Interview for DSM-IV Axis 1 Disorders (SCID). New York State Psychiatric Institute, Biometrics Research: New York.

Vasterling JJ, Duke LM, Brailey K, Constans JI, Allain Jr AN, Sutker PB (2002). Attention, learning, and memory performances and intellectual resources in Vietnam veterans: PTSD and no disorder comparisons. Neuropsychology 16: 5-14.

Veltmeyer MD, Clark CR, McFarlane AC, Felmingham KL, Bryant RA, Gordon E (2005). Integrative assessment of brain and cognitive function in post-traumatic stress disorder. $J$ Integr Neurosci 4: 145-159.

Vythilingam M, Vermetten E, Anderson GM, Luckenbaugh D, Anderson ER, Snow J et al (2004). Hippocampal volume, memory, and cortisol status in major depressive disorder: effects of treatment. Biol Psychiatry 56: 101-112.

Wager TD, Smith EE (2003). Neuroimaging studies of working memory: a meta-analysis. Cognitive, Affective and Behavioral Neuroscience 3: 255-274.

Watzka M, Bidlingmaier F, Beyenburg S, Henke RT, Clusmann H, Elger CE et al (2000). Corticosteroid receptor mRNA expression in the brains of patients with epilepsy. Steroids 65: 895-901.

Wechsler D (1997). Manual for the Wechsler Memory Scale, 3rd edn. The Psychological Corp: San Antonio.

Wolkowitz OM, Reus VI, Weingartner H, Thompson K, Breier A, Doran A et al (1990). Cognitive effects of corticosteroids. Am J Psychiatry 147: 1297-1303.
Yehuda R, Keefe RS, Harvey PD, Levengood RA, Gerber DK, Geni J et al (1995). Learning and memory in combat veterans with posttraumatic stress disorder. Am J Psychiatry 152: 137-139.

Yehuda R, Teicher MH, Trestman RL, Levengood RA, Siever LJ (1996). Cortisol regulation in posttraumatic stress disorder and major depression: a chronobiological analysis. Biol Psychiatry. 40: 79-88.

Yehuda R, Siever LJ, Teicher MH, Levengood RA, Gerber DK, Schmeidler J et al (1998). Plasma norepinephrine and 3methoxy-4-hydroxyphenylglycol concentrations and severity of depression in combat posttraumatic stress disorder and major depressive disorder. Biol Psychiatry 44: 56-63.

Yehuda R (2002). Current status of cortisol findings in post-traumatic stress disorder. Psychiatr Clin North Am 25: 341-368.

Yehuda R, Golier JA, Halligan SL, Meaney M, Bierer LM (2004a). The ACTH response to dexamethasone in PTSD. Am J Psychiatry 161: 1397-1403.

Yehuda R, Golier JA, Yang RK, Tischler L (2004b). Enhanced sensitivity to glucocorticoids in peripheral mononuclear leukocytes in posttraumatic stress disorder. Biol Psychiatry 55: $1110-1116$.

Yehuda R, Golier JA, Tischler L, Stavitsky K, Harvey PD (2005a). Learning and memory in aging combat veterans with PTSD. $J$ Clin Exp Neuropsychol 27: 504-515.

Yehuda R, Golier JA, Kaufman S (2005b). Circadian rhythm of cortisol in Holocaust survivors. Am J Psychiatry 162: 998-1000.

Yehuda R, Golier JA, Tischler L, Harvey PD, Newmark R, Yang RK et al (2006a). Hippocampal volume in aging combat veterans with and without PTSD: relation to risk and resilience factors. J Psychiatr Res 41: 435.

Yehuda R, Tischler L, Golier JA, Grossman R, Brand S, Kaufman S et al (2006c). Longitudinal assessment of cognitive performance in Holocaust survivors with and without PTSD. Biol Psychiatry 60: 714-721.

Yehuda R, Yang RK, Buchsbaum MS, Golier JA (2006b). Alterations in cortisol negative feedback inhibition as examined using the ACTH response to cortisol administration in PTSD. Psychoneuroendocrinology 31: 447-451.

Yehuda R, Morris A, Labinsky E, Zemelman S, Schmeidler J (in press). Ten year follow-up study of cortisol levels in aging Holocaust survivors with and without PTSD. J Traumatic Stress.

Yehuda R, Teicher MH, Golier JA, Bierer LM (in preparation). Chronobiological analysis of cortisol and ACTH in aging combat veterans. Unpublished manuscript. 